\title{
Characterization of Wheat Gluten Proteins by HPLC and MALDI TOF Mass Spectrometry
}

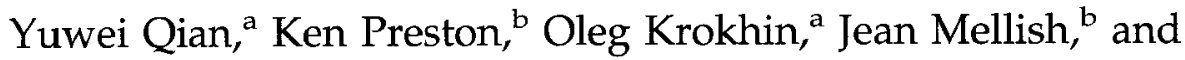 \\ Werner Ens ${ }^{a}$ \\ ${ }^{a}$ Department of Physics and Astronomy, University of Manitoba, Winnipeg, Manitoba, Canada \\ ${ }^{\mathrm{b}}$ Grain Research Laboratory, Canadian Grain Commission, Winnipeg, Manitoba, Canada
}

We have performed a detailed characterization and identification of wheat gluten proteins obtained from the Teal variety of Canadian hard red spring wheat. RP-HPLC separation of the sample into 35 fractions has reduced the spectral complexity; this was followed by MALDI mass spectrometry (MS), which showed the presence of six or fewer resolved protein components above $20 \mathrm{kDa}$ in each RP-HPLC fraction, giving a total of $93 \mathrm{MS}$ resolved peaks. These included 17 peaks in the $\omega$-gliadin fractions (F1-4), 12 in the high molecular weight (HMW) glutenin subunit fractions (F5-8), 59 in the $\alpha$ - and $\beta$-gliadins and low molecular weight (LMW) glutenin subunit fractions (F9-31) and 5 peaks in the $\gamma$-gliadin fractions (F32-35). Peptide maps of tryptic digests of HPLC fractions were obtained from a tandem quadrupole time-of-flight mass spectrometer (MALDI QqTOF MS) and were submitted to the ProFound search engine. HMW glutenin subunits including Ax2*, Dx5, Bx7, and Dy10 (consistent with the known profile of Teal), and LMW glutenin subunits including six from group 3 type II and 1 from group 2 type I, were identified with reasonable sequence coverage from HPLC fraction $5,7,17$, and 18. The identities of the peptides attributed to selected gluten proteins were confirmed using MS/MS with BioMultiView to match the predicted and measured partial amino acid sequences. Because of incomplete wheat DNA databases, many wheat gluten proteins could not be identified. These results suggest that the combination of RP-HPLC with MS and MS/MS techniques is a promising approach for the characterization of wheat gluten proteins. (J Am Soc Mass Spectrom 2008, 19, 1542-1550) @ 2008 American Society for Mass Spectrometry

$\mathrm{T}$ The gluten (storage) proteins in wheat are responsible for imparting the unique visco-elastic properties that allow the production of leavened bread, pasta, noodle, and related products. The two major groups of these proteins include the monomeric gliadins and the polymeric glutenins consisting of interchain disulphide bonding low molecular weight (LMW) and/or high molecular weight (HMW) glutenin subunits [1]. Electrophoretic and RP-HPLC patterns of gluten proteins and their gliadin and LMW glutenin subunit components are complex, showing a large number of components, while simpler patterns are evident for the HMW glutenin proteins [2]. The complexity of these patterns can be attributed to the presence of two or three sets of homologous chromosomes in durum and common wheat, respectively, and to additional polymorphism related to mutation of gluten protein genes into many allelic forms [3]. Gliadin patterns have been extensively used to provide definitive identification of all but the most closely genetically related varieties [1]. Specific peaks or patterns, particularly those of the HMW glutenin subunits, have been

Address reprint requests to Dr. W. Ens, TOF Laboratory, 506 Allen Bldg, Department of Physics and Astronomy, University of Manitoba, Winnipeg, Manitoba R3T 2N2, Canada. E-mail: ens@cc.umanitoba.ca associated with differences in processing performance among wheat classes and varieties, allowing their use as quality markers [4-7].

There are several difficulties associated with proteomic analysis of wheat storage proteins, including the limited databases available, the limited number of basic residues (particularly in the LMW glutenin subunits), the complexity resulting from the presence of sets of homologous proteins, and the presence of repeating motifs. In spite of this, wheat proteins have been widely studied using HPLC $[1,8]$, and mass spectrometry techniques are now widely applied alone or in combination with other chromatographic techniques in proteomic studies of wheat [9-12]. Previous studies have established that MALDI-TOF MS can resolve a large number of wheat gliadins and glutenin subunits [9]. MALDI-MS of purified HMW subunits yielded molecular mass determinations consistent with their cDNA derived amino acid sequences [10]. The use of MALDI-MS for mapping tryptic peptides of HMW subunits demonstrated good agreement between MS measured molecular weights and those derived from the gene sequences [11, 12]. Tryptic digests have also been analyzed using ESI mass spectrometry in MS and MS/MS modes to confirm amino acid sequences of HMW subunits [12]. In this study we demonstrate the 
viability of detailed characterization and identification of wheat gluten proteins by RP-HPLC followed by high-resolution MALDI mass spectrometry (MS and MS/MS) of the resulting protein fractions and their trypsin peptide digests. For this study, we have selected the CDC Teal variety, which is a registered crop under Canada Western Red Spring Wheat. It is a high protein bread wheat variety that was developed by the Crop Development Centre at the University of Saskatchewan. It is one of the top five crops in Canada.

\section{Methods}

\section{Reagents and Chemicals}

All the solvents used for sample preparations and HPLC, 1-propanol (Caledon, Georgetown, ON, Canada) and acetonitrile (Fisher Scientific, Canada), were distilled or HPLC grade. The reagents for reduction and alkylation, dithiothreitol (DTT) and iodoacetamide (Sigma Chemical Co., St. Louis, MO, USA), were enzyme grade. Ammonium hydrogencarbonate was from Sigma-Aldrich Inc. (St. Louis, MO, USA). Photometric grade trifluoroacetic acid (TFA) was from SigmaAldrich. Sequencing grade Protease was trypsin from Roche Diagnostics Co. (Indianapolis, IN, USA); 2,5dihydroxybenzoic acid (DHB) and sinapinic acid from Sigma-Aldrich were used as matrices. The all-in-1 protein standard kit used for MALDI-TOF calibration was from Ciphergen Biosystems Inc. (Fremont, CA, USA). Peptides for MALDI-QqTOF calibration were obtained from American Peptide Co. (Sunnyvale, CA, USA) (enkephalin) and Sigma-Aldrich (Substance P and bee venom melittin).

\section{Protein Extraction}

Gluten proteins were extracted from a Canadian hard red spring bread wheat variety (CDC Teal). Seed was ground on an Udy cyclone mill fitted with a $1 \mathrm{~mm}$ sieve. Approximately $1 \mathrm{~g}$ of ground wheat and $6 \mathrm{~mL}$ of $50 \%$ 1-propanol containing 1\% DTT were combined in an Oak Ridge $30 \mathrm{~mL}$ centrifuge tube (Nalge Co., Rochester, $\mathrm{NY}, \mathrm{USA}$ ) and held in a water bath at $60^{\circ} \mathrm{C}$ for $0.5 \mathrm{~h}$ with intermittent vortexing every $10 \mathrm{~min}$. The mixture was then centrifuged for $10 \mathrm{~min}$ at $8000 \times g$ at $25^{\circ} \mathrm{C}$ and the supernate was removed and filtered through a 0.45 $\mu \mathrm{m}$ syringe filter (Whatman, Clifton, NJ, USA) before HPLC analysis.

\section{RP-HPLC}

Extracts were analyzed on a Waters chromatography system (600S Controller, 616 Pumps and 717 Autosampler) (Waters Corporation, New Castle, DE, USA) controlled with Millennium software using a procedure similar to that of Marchylo et al. [8]. Three aliquots $(3 \times$ $5 \mu \mathrm{L}$ ) of the filtered extract were injected into a Zorbax SB300-C18 reversed-phase column $(15 \mathrm{~cm} \times 4.6 \mathrm{~mm}$ i.d. $)$ (Agilent Technology, Palo Alto, CA, USA) and separation was carried out at $60^{\circ} \mathrm{C}$ using a linear gradient of aqueous acetonitrile containing $0.1 \%$ TFA at a flow rate of $1 \mathrm{ml} / \mathrm{min}$. The acetonitrile concentration was increased from $24 \%$ to $50 \%$ over $108 \mathrm{~min}$ and held constant thereafter. Column effluent was monitored at $210 \mathrm{~nm}$. Thirty-five major peaks from the HPLC chromatogram were identified and collected individually (Figure 1). The concentrations of protein in most HPLC elute fractions were from 10 to $80 \mathrm{ng} / \mu \mathrm{L}$, measured by use of a BCA Protein Assay Reagent Kit (Pierce Biotechnology, Rockford, IL, USA).

\section{MALDI-TOF of Intact Proteins}

Preliminary studies showed that alkylation of the reduced protein from RP-HPLC did not interfere with the determination of mass measurements. Two hundred $\mu \mathrm{L}$ of each HPLC fraction was vacuum-concentrated in a Speed Vac (Model SC110, Savant) to almost dryness and then re-constituted in $70 \mu \mathrm{L}$ of $50 \%$ acetonitrile containing $0.1 \%$ TFA with vortexing to dissolve the proteins. The reconstituted fractions had protein concentrations varying from 30 to $240 \mathrm{ng} / \mu \mathrm{L}$. On a metal surface sample chip (made in our lab), $1 \mu \mathrm{L}$ of reconstituted sample was deposited onto a designated spot and dried. On the top of the dried sample, $0.5 \mu \mathrm{L}$ of freshly prepared sinapinic acid $(30 \mathrm{mg} / \mathrm{mL})$ was added and air-dried before loading the chip onto a Ciphergen

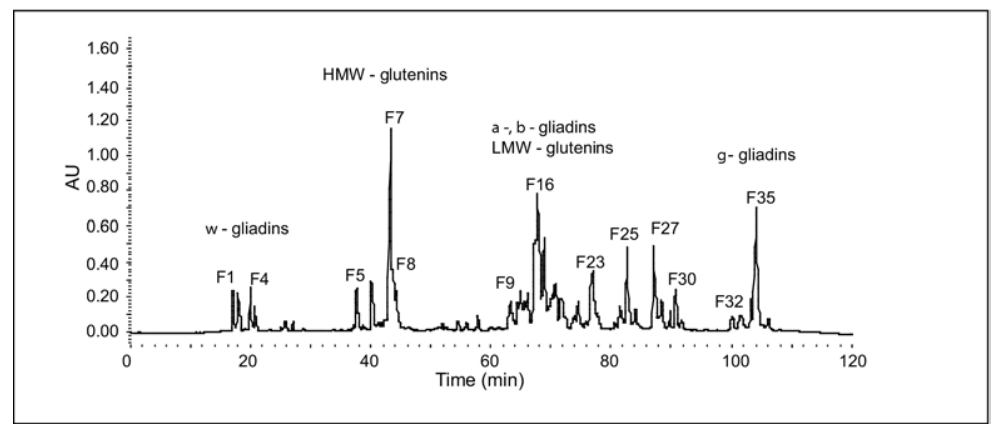

Figure 1. Reversed-phase HPLC profile of reduced gluten extract from CDC Teal. 
MALDI-TOF instrument (Model PBS-II, Ciphergen Biosystems Inc., Fremont, CA, USA).

MALDI-TOF MS in positive ion mode was optimized in the mass range of 10 to $60 \mathrm{kDa}$ for $\alpha-, \beta-$, and $\gamma$-gliadins and LMW glutenin subunit fractions. For the larger $\omega$-gliadin and HMW glutenin subunit fractions, the optimal mass range was set from 40 to $120 \mathrm{kDa}$. External calibration was performed using the protein calibration kit (Ciphergen Biosystems Inc.) containing proteins with masses after protonation of 12,360.2 (horse cytochrome $c$ ), 16,951.5 (horse muscle myoglobin), 35,688.0 (rabbit GAPDH), 66,433.0 (bovine serum albumin), and 116351.0 (E. coli $\beta$-galactosidase). Approximately 75 shots on each sample spot were used to obtain spectra. Delayed extraction using a pulse lag time of 1328 ns was used to enhance resolution [3].

\section{Peptide Mass Mapping (MS) and Peptide Fragmentation (MS/MS) Using MALDI-QqTOF}

One hundred $\mu \mathrm{L}$ from each HPLC fraction was vacuum concentrated (Speed Vac) to almost dryness and then reconstituted in $5 \mu \mathrm{L}$ of $50 \%$ acetonitrile containing $0.1 \%$ TFA with vortexing to dissolve the proteins. Five $\mu \mathrm{L}$ of $100 \mathrm{mM}$ ammonium hydrogencarbonate was added into the solution to optimize conditions for tryptic digestion. The gluten proteins in each fraction were then reduced by adding $1.1 \mu \mathrm{L}$ of $100 \mathrm{mM}$ DTT followed by incubation in a water bath at $60^{\circ} \mathrm{C}$ for 45 min with intermittent vortexing every $10 \mathrm{~min}$. The reduced proteins were alkylated by adding $11.1 \mu \mathrm{L}$ of $100 \mathrm{mM}$ iodoacetamide and keeping the solution in the dark for $30 \mathrm{~min}$ with intermittent vortexing every 10 min. The reduced and alkylated proteins were incubated with $1.5 \mu \mathrm{L}$ of trypsin $(100 \mathrm{ng} / \mathrm{ul})$ at $37^{\circ} \mathrm{C}$ for $20 \mathrm{~h}$. Tryptic digests $(1 \mu \mathrm{L})$ were deposited on a metal surface sample plate, air-dried, and $160 \mathrm{mg} / \mathrm{mL}$ DHB $(1$ $\mu \mathrm{L})$ was added on top with air drying. Samples were then analyzed in positive ion mode using a MALDI QqTOF prototype instrument constructed in collaboration with MDS SCIEX [13]. The instrument was used to obtain high-resolution spectra in the single-MS and tandem MS modes. External calibration was performed using protonated ions of dalargin, Substance $P$, and bee venom melittin with monoisotopic masses of 726.394, 1347.736, and 2845.762, respectively. Peptide spectra were obtained using 600 to 1200 shots while MS/MS spectra of were obtained using 4000 to 6000 shots. MSMS data were interpreted using BioMultiView, a commercial program from MDS-SCIEX. Monoisotopic masses from this instrument are reported for all peaks unless otherwise stated.

\section{Results and Discussion}

\section{Analysis of Intact Proteins and Protein Subunits}

The RP-HPLC profile of the reduced CDC Teal wheat gluten protein extract is shown in Figure 1. The 35
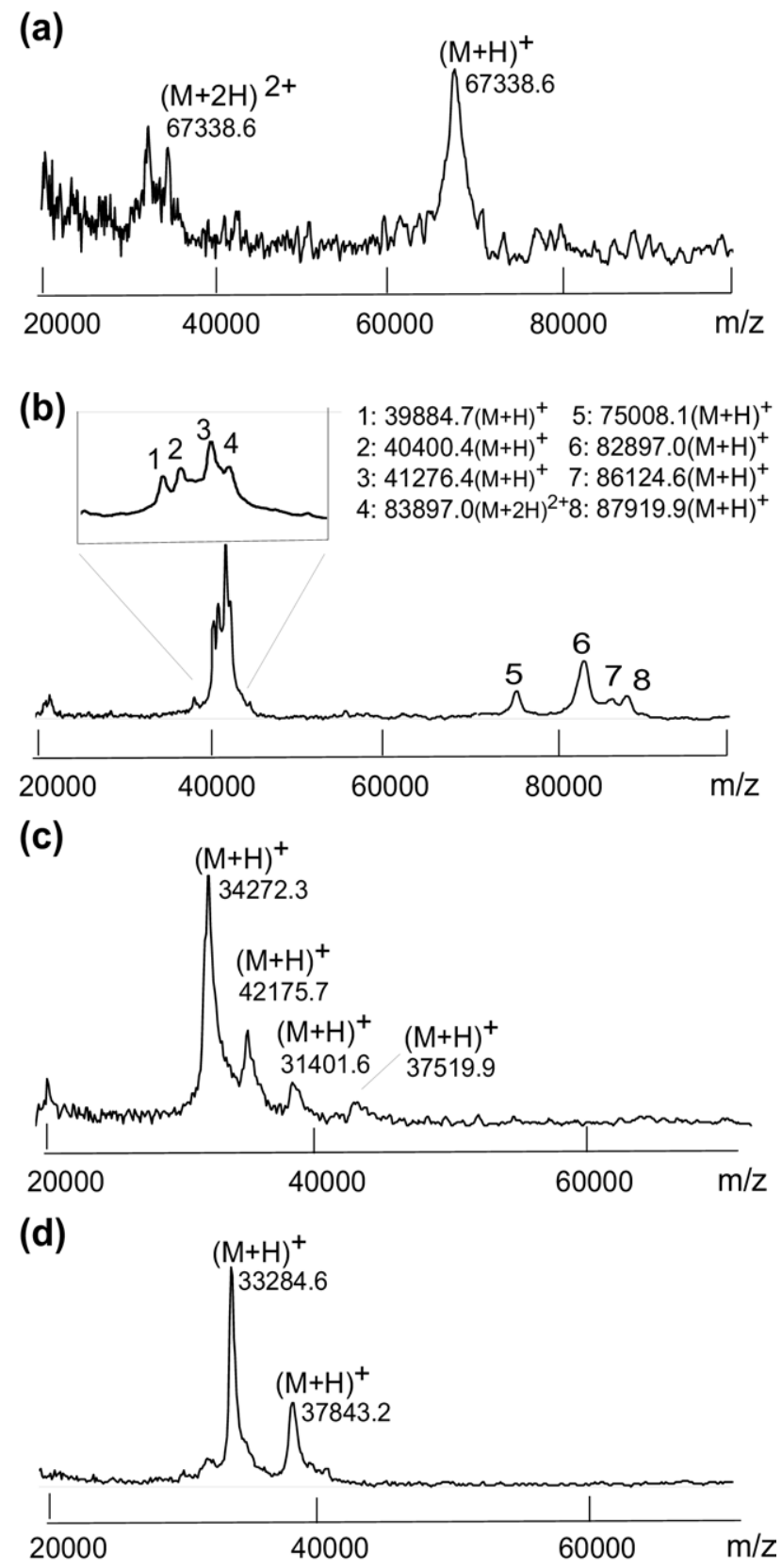

Figure 2. Mass spectra of intact proteins from selected HPLC fractions of Teal by MALDI TOF mass spectrometry: (a) fraction 5, (b) fraction 7, (c) fraction 17, and (d) fraction 18.

fractions collected, representing major peaks, can be divided into four groups based on their retention times $[2,8]$ : the $\omega$-gliadins (fractions F1-F4), the HMW glutenins (F5-F9), a mixture of $\alpha$ - and $\beta$-gliadins and LMW glutenins (F9-F31), and the $\gamma$-gliadins (F32-F35).

Each fraction was analyzed by MALDI using linear TOF to examine intact proteins. Examples of spectra for four of the fractions are shown in Figure 2. The spectrum from each fraction resolved between 1 and 6 protein components with molecular masses over 20 $\mathrm{kDa}$. The number of components observed in the mass spectra and their molecular weight range is summarized in Table 1 for each of the four groups of fractions. 
Table 1. MALDI-TOF characteristics of gluten protein fractions from RP-HPLC

\begin{tabular}{lccc}
\hline \multicolumn{1}{c}{ Region } & Fractions & Number of major peaks & Molecular weight (kDa) (MALDI-TOF) \\
\hline \hline$\omega$-gliadins & F1-F4 & 10 peaks & 7 peaks \\
& & 7 peaks & $42-52$ \\
HMW-glutenins & F5-F8 & 5 peaks & $32-42$ \\
& & 59 peaks & $67-88$ \\
$\alpha-, \beta$-gliadins, LMW-glutenins & F9-F31 & 5 peaks \\
$\gamma$-gliadins & F32-F35 & $30-38$
\end{tabular}

The $\omega$-gliadin fractions showed molecular masses in two distinct ranges: $30-35 \mathrm{kDa}$ and $42-52 \mathrm{kDa}$. These values are considerably lower than previous estimates of the $\omega$-gliadin molecular masses based on SDS PAGE results $(45-75 \mathrm{kDa})$ due to anomalous migration in SDS PAGE $[14,15]$. However, more recent studies by Wieer et al. [16], based on MALDI-TOF analysis, showed a range of $36-44 \mathrm{kDa}$ for $\omega-1,2$ type gliadins and $44-55$ $\mathrm{kDa}$ for $\omega-5$ type gliadins, more consistent with our values, although still somewhat higher.

The $m / z$ values from the HMW glutenin fractions also fell into two ranges, with 7 peaks ranging from about 32 to $42 \mathrm{kDa}$ and 5 peaks ranging from 67 to 88 $\mathrm{kDa}$. In addition to the peaks shown in Figure 2 for fractions F5 and F7, the mass spectrum of fraction F6 showed two peaks in the lower mass range, and the spectrum of F8, which eluted as a shoulder after F7, had one additional peak in the lower mass range not present in the spectrum of F7. The higher mass range is consistent with values derived from HMW glutenin gene sequences which show putative masses ranging from 67 to $74 \mathrm{kDa}$ for $\mathrm{y}$-type HMW glutenin subunits and 83 to $88 \mathrm{kDa}$ for $\mathrm{x}$-type HMW glutenin subunits [7]. The five observed peaks are consistent with the number of HMW subunits expressed in CDC Teal as determined by genetic analysis and SDS PAGE [Lukow, O., private communication]. The origin of the peaks in the lower mass range are not yet understood. They may represent $\omega$-gliadins that can overlap with HMW glutenins in RP-HPLC [8], and/or other wheat protein components with similar hydrophobicities such as HMW albumins, which are also extracted in 50\% 1-propanol/1\% DDT [10].

The third group of fractions (F9-31) consisting of $\alpha$ - and $\beta$-gliadins and LMW glutenin subunits gave 59 peaks ranging in molecular mass from about 29 $\mathrm{kDa}$ to $42 \mathrm{kDa}$. This range is also somewhat lower than the 36-44 kDa range expected as determined by SDS-PAGE [7], but consistent with MALDI-TOF MS results showing major gliadin peaks in the $30-39 \mathrm{kDa}$ range and major LMW glutenin subunit peaks in the $30-43 \mathrm{kDa}$ range [5].

The four $\gamma$-gliadin fractions showed five distinct peaks with masses between 30 and $38 \mathrm{kDa}$. This range is similar to that reported for $\alpha$ - and $\beta$-gliadins and LMW glutenin subunits [7].

Although the most effective separation of gluten protein components is still obtained by 2-D electrophoresis [2], the combination RP-HPLC and MS seems to compare favorably with this technique. Dachkevitch et al. separated about 45 gliadin components using 2-D electrophoresis in Neepawa [14], a Canadian red spring wheat variety closely related to the CDC Teal used in this study. An advantage of the MS approach is that the measured mass is less sensitive to systematic effects than the position in a gel, and is therefore expected to be more effective as a characteristic marker for specific gluten proteins.

\section{Protein Identifications}

Each RP-HPLC fraction was subjected to tryptic digestion and then analyzed by MALDI QqTOF. The resulting peptide maps were then searched against a protein database (NCBI or SWISS-PROT) for matching proteins using the ProFound search engine [17]. Because each fraction contained multiple proteins, a tight mass tolerance of 30 ppm was necessary for peptide peak identification to reduce false positives. Fortunately, the accuracy of the QqTOF instrument is consistent with this level of accuracy. The databases currently accessible to ProFound for wheat proteins are far from complete, and as a result, most fractions did not result in a protein identification. Nevertheless, positive search responses were obtained from fractions F5, F7, F17, and F18. The MALDI QqTOF peptide maps for fraction F5, F7, F17 and F18 are shown in Figure 3.

\section{HMW Protein Identities}

Among the HMW protein subunits tentatively identified were Dy10 (P10387) from F5 and 1Ax1 (S15720), Ax2*(AAB02788), Dx5 (P10388), and Bx7 (A30843) from F7. The HMW protein subunits are subdivided into high $\mathrm{M}_{\mathrm{r}} \mathrm{x}$-type and low $\mathrm{M}_{\mathrm{r}} \mathrm{y}$-type subunits [3]. Two genes, encoding an x-type and y-type, are present on the $1 \mathrm{~A}, 1 \mathrm{~B}$, and $1 \mathrm{D}$ chromosomes of hexaploid bread wheat [3]. All cultivars of wheat contain six HMW protein subunits, but only 3,4 , or 5 subunits are present because some of the genes are silent (1Ay gene is silent in all bread wheat varieties). The $1 \mathrm{Ax} 1$ gene is associated with good breadmaking quality but is not present in many cultivars [3, 18].

Sequence coverage ranged from $10 \%$ to $36 \%$ (Table 2 ). The relatively low sequence coverage obtained for these subunits is mainly due to the scarcity of arginine and lysine cleavage points in the large central domain of HMW glutenin subunits. This domain contains multi- 

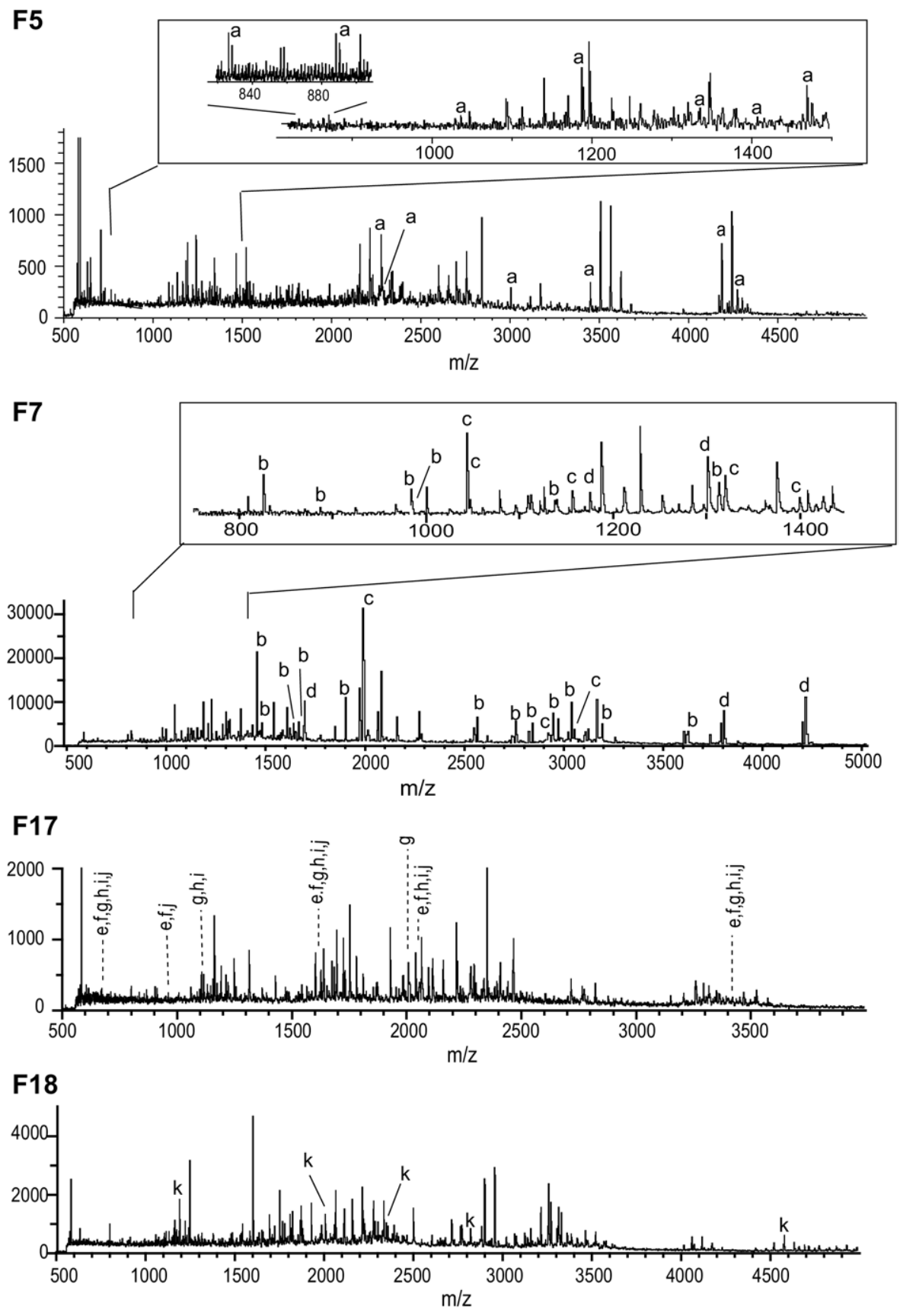

Figure 3. Tryptic peptide maps from fractions 5, 7, 17, and 18 by MALDI-QqTOF mass spectrometry.

ple copies of hexapeptide (PGQGQQ), nanopeptide (GYYPTSPQQ), and (in x-type subunits only) tripeptide (GQQ) motifs, and only rare arginine and lysine cleavage sites [19]. Trypsin cleavage in this region produces mainly large peptides, which are above the $5000 \mathrm{Da}$ limit used by the search engine. When the observed peptide map is compared with the predicted map containing only peptides below $5000 \mathrm{Da}$, the coverage ranges from $50 \%$ for Dx5 to well over $70 \%$ for $1 \mathrm{Ax} 1$, Ax2*, and Dy10 (Table 2).

Additional peptides above $5000 \mathrm{Da}$ were also observed but with lower mass accuracy because of the weak signal intensity. These were compared with predicted tryptic fragments in this mass range based on average, rather than monoisotopic masses. A peak at $\mathrm{m} / \mathrm{z} 8587$ in the spectrum of fraction F5 is consistent with the tryptic peptide from residues 390 to 469 in the subunit Dy10. In the mass spectrum of the F7 fraction, peaks at $\mathrm{m} / \mathrm{z} 7821$ and $\mathrm{m} / \mathrm{z} 8094$ are consistent with tryptic peptides containing residues 298 to 371 , and 372 to 448 from the subunit Bx7; a peak at $\mathrm{m} / \mathrm{z} 8534$ is consistent with residues 735 to 812 in Dx5; and a peak at $\mathrm{m} / \mathrm{z} 8533$ is consistent with a predicted tryptic fragment from both $\mathrm{Ax}^{*}$ (residues 270 to 348 ) and $1 \mathrm{Ax} 1$ (residues 
Table 2. Identification@F@MW@lutenin@ubunits@ased@n@eptide@atterns@btained@n@he@MALDI@qTOF@nstrument@nd@ntact mass@no@lkylation)@neasured@ith@inear@MALDIđOF

\begin{tabular}{|c|c|c|c|c|c|c|c|c|}
\hline Subunit & Code & $\mathrm{Z}^{\mathrm{a}}$ & HPLC fraction & $\begin{array}{c}\text { Peptide } \\
\text { coverage (\%) }\end{array}$ & $\begin{array}{c}\text { Maximum } \\
\text { coverage }^{\text {b }}(\%)\end{array}$ & $\begin{array}{l}\text { Obs'd mass } \\
\text { (Da) }\end{array}$ & $\begin{array}{l}\text { Calc. mass }{ }^{\mathrm{c}} \\
\text { (Da) }\end{array}$ & $\Delta \mathrm{m}(\mathrm{Da})$ \\
\hline Dy10 & P10387 & 2.31 & F5 & 36 & 44 & 67401 & 67475 & 64 \\
\hline$A \times 1$ & 003872 & 2.08 & F7 & 26 & 31 & 87919 & 87679 & 240 \\
\hline$A \times 2 *$ & AAB 02788 & 2.08 & F7 & 31 & 38 & 86124 & 86317 & 193 \\
\hline Dx5 & P10388 & 2.34 & F7 & 10 & 20 & 87919 & 87191 & 728 \\
\hline $\mathrm{Bx} 7$ & JN0690 & 2.34 & F7 & 18 & 25 & 82897 & 82863 & 34 \\
\hline
\end{tabular}

aThe Z-score is used by ProFound as an indicator of the quality of the search result. It represents the number of standard deviations that the selected goodness-of-fit metric exceeds the mean value of the same metric for a random population. Thus, by standard statistics, for a normal distribution of random proteins, a Z-score of 1.65 represents $95 \%$ confidence that the protein is not random; $Z=2.3$ represents $99 \%$ confidence.(http:// cebs.niehs.nih.gov/cebs-browser/help/proteomics/profound_mascot_info.html).

${ }^{\mathrm{b}}$ Coverage observed if all peptides under mass $5000 \mathrm{Da}$ are observed.

'Based on the DNA sequence.

276@o(354).@nly@ne@Ax@ene@llele@1Ax1@r(Ax2*)@s present@n@ach@heat@ultivar,@ut@ccording@o@(D) sequence@tudy@n@Ax1@ind@Ax2*@18],@he@wo@ubunits@have@ery@lose@homology, @haring@many@ryptic peptides@(@) two甲eptides@ere@bserved 9 rom 9 x2*@t@n/z 2761@nd 2842@hat@re@ot@resent $₫ n @ A x 1, @$ hereas@one@) $₫$ (4he observed@eptides@ere@nique@o@Ax1.@his@uggests that $@ A \times 2 * @ s @ r e s e n t, @ n d @ A x 1 @ s @$ ot.

To@onfirm@he@dentities@f@he@Ax@eptides, @urther analyses@f@ryptic@eptides@ssigned@o@x2*@nd@Ax1 were@carried@out@using@tandem@mass@spectrometry (MS/MS).®BioMultView@as@sed@o@xtract@mino@cid sequence@ata@rom @he@pectra.đhe@MS/MS@pectrum of@the@1 138@Da@peptide, Cassigned@to@1 Ax1/Ax2*@is shown@nథFigure@4. Gts@educed@equence@ata@match perfectly@with@the@DNA@derived@sequence@for@both subunits.(Both@-@and(b-ions@re@labeledథor@larity,(but all@-ions@ere@lso@dentified@n@he@MS/MS@pectrum. Results@f(8థeptides@ssigned@o@x2*@re@ummarized inđTableC8.CThe@osition@f@ach@isted@eptide@orresponds@to@the@subunit@before@removal@of@the@signal peptide.đhe@equence@ata@f@11@8@peptides@erfectly matched@he@NA-translated@rimary@equence@f@he predicted@Ax2*@eptides@dentified@y@mass@mapping.
As@nentioned@bove,@wo@f@hese@eptides@2761@nd 2842థa)@re@ot@resent@n $₫ A x 1$.

The@redicted@masses@f@he@ntact@ubunits@denti-

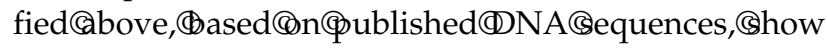
good@greement@ith $\oplus$ he@bserved@n/z values@btained

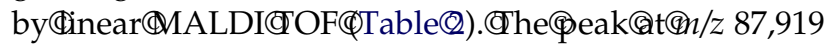

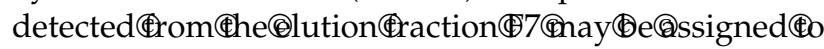
two@ubunits@Ax1@nd@x5.@However, (he@eak@t@n/z 86,124@s@only@n@good@greement@with@the@mass@xpected@for@Ax2*.CSince@only@one@Ax@gene@allele@is expected,@his@esult@ombined@with@he@esults@f@he peptide@nalysis@bove@trongly@uggests@hat $\mathrm{CAx} 2 *$ @s present,@nd@Ax1@s@bsent.

MS/MS@nalyses@vere@1so@arried@ut@n@eptides assigned@o@he@ubunits@B7@andФx5.@n@hese@ases, weak@ignal@intensity@nade@omplete@equence@nalysis impossible.GHowever, (based@n@peaks@bove@n/z 500, partial@equence@natches@vere@onfirmed@or@eptides observed@at@m/z 1302@(y5 y11,@b4 b11), (m/z 1698 (y5 y16, Cb5 b16), $\mathrm{cm} / \mathrm{z} 3322 \propto(\mathrm{y} 5 \sim 13, \mathrm{Cy} 15, \mathrm{Cy} 18 \sim \mathrm{y} 22$, y24 y27, ( $\mathrm{y} 29)$, ( and $\odot \mathrm{m} / \mathrm{z} \quad 3806 \odot(\mathrm{y} 5 \sim \mathrm{y} 35$, ( b5 b31,

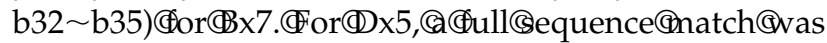
confirmed@or@he@peptide@t@m/z 1990@y1 18)@while partial@natches@bove@/z 500@vere@btained@or@eaks

\section{QQPGQGQQLR}

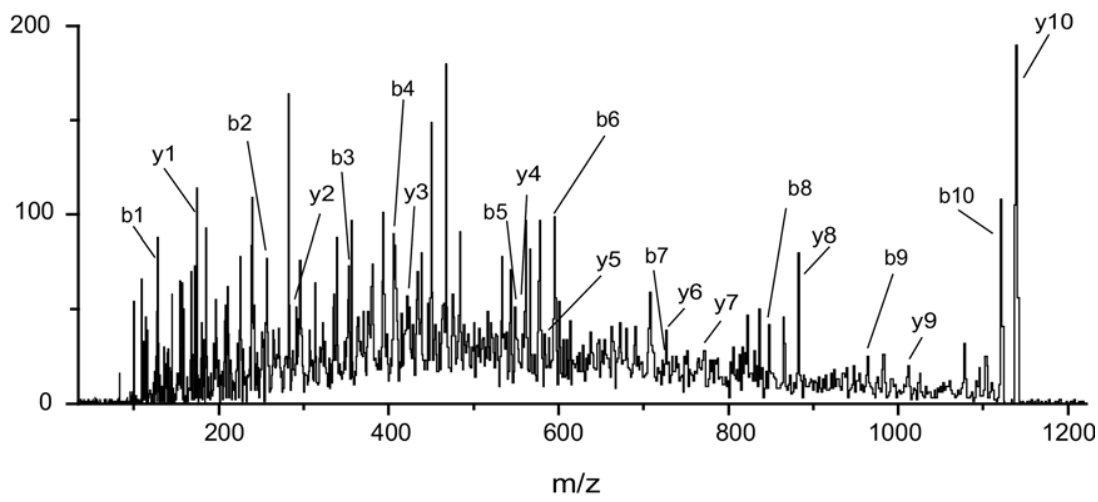

Figure 4. MS/MS of the peptide at 1138 Da from Ax2* or 1Ax1 HMW glutenin subunit by MALDI-QqTOF mass spectrometry. 
Table 3. Observed amino acid sequences from MS/MS measurements using MALDI QqTOF and the corresponding association with predicted sequences in both $1 \mathrm{Ax} 1$ and Ax2* from the databases. The peptides are assumed to be alkylated

\begin{tabular}{|c|c|c|c|}
\hline Obs'd mass (Da) & Amino acid sequence from MALDI QqTOF & Ax2* position & Ax1 position \\
\hline 826 & OWLQPR & $725-730$ & $740-745$ \\
\hline 887 & QGQQSGQR & $349-356$ & $355-362$ \\
\hline 982 & ELQEHSLK & $34-41$ & $34-41$ \\
\hline 984 & QVVDQQLR & $45-52$ & $45-52$ \\
\hline 1138 & QQPGQGQQLR & $195-204$ & $201-210$ \\
\hline 1456 & AQQLAAQLPAMCR & $792-804$ & $807-819$ \\
\hline 1482 & QGQQGQQSGQGQPR & $205-218$ & $211-224$ \\
\hline 1623 & DVSPECQPVGGGPVAR & $53-68$ & $53-68$ \\
\hline 1668 & QQDQOSGQGQOPGQR & $357-371$ & $363-377$ \\
\hline 1902 & YYPTSPQQPGQEQQPR & $390-405$ & $396-411$ \\
\hline 1990 & QPGYYSTSPOQLGQGQPR & $372-389$ & 378-395 \\
\hline 2564 & GQQGQQSGQGQQLGQGQQGQQPGQK & $245-269$ & $251-275$ \\
\hline 2761 & QLQQPEQGQQGQQPEQGQQGQQQR & $406-429$ & $\times$ \\
\hline 2842 & QPGYYPTSPWOPEQLQQPTQGQQR & $171-194$ & $\times$ \\
\hline 2944 & YYPTSSQQPGQLQQLAQGQQGQQPER & $219-244$ & $225-250$ \\
\hline 3209 & GGSFYPGETTPPQQLQOSILWGIPALLRR & 80-108 & $80-108$ \\
\hline 3641 & QQDQOSGQGQQPGQRQPGYYSTSPQQLGQGQPR & 357-389 & 363-395 \\
\hline 4349 & QYEQOVVVPPKGGSFYPGETTPPQQLQQSILWGIPALLR & 69-107 & 69-107 \\
\hline
\end{tabular}

at $m / z 1044(\mathrm{y} 4 \sim \mathrm{y} 8, \mathrm{~b} 4 \sim \mathrm{b} 8), m / z 1157(\mathrm{y} 5, \mathrm{y} 6, \mathrm{y} 8, \mathrm{y} 10$, $\mathrm{b} 4 \sim \mathrm{b} 8)$, and $m / z 1313(\mathrm{y} 4 \sim 6, \mathrm{y} 9, \mathrm{y} 11, \mathrm{~b} 4 \sim \mathrm{b} 6, \mathrm{~b} 11)$.

Genetic and SDS PAGE studies have identified the HMW glutenin subunits in CDC Teal as Ax2*, Bx7, Dx5, By8, and Dy10 [Lukow, O., private communication]. This is in good agreement with our results except that By 8 could not be identified since no DNA sequence for this subunit has yet been published. However, a peak at mass $74.61 \mathrm{kDa}$ was observed by linear MALDI TOF from the fraction F7 (Figure 2) that closely corresponds to the mass of the By8 subunit determined by capillary electrophoresis using Ferguson plot analysis [15].

\section{LMW Protein Identities}

LMW glutenin subunits were identified from database searches against peptide maps obtained from fractions F17 and F18. In F17, six group 3 type II subunits (BAB78740, BAB78741, BAB78742, BAB78743, BAB78744, and BAB78745) were tentatively identified and in F18, one group 2 type I subunit (BAB78738) was identified. Coverage with peptides below 5000 Da ranged from $22 \%$ to $26 \%$ of the sequence (Table 4). Here again, the scarcity of arginine and lysine cleavage points in the repetitive proline-rich regions in the LMW glutenin subunits [7] results in relatively few predicted tryptic peptides below the 5000 Da limit of the search engine. With the exception of one of the subunits, all the predicted peptides in this mass range were observed; 3 of 6 were observed for BAB78738 (Table 4).

The DNA sequences for the group 3 type II LMW subunits show very strong similarities [20], so the peptide mass maps should be expected to have significant overlap. As a result, the data do not provide definitive evidence that all of the expected subunits are present. Table 5 shows the complete list of predicted peptides used to tentatively identify the subunits from fraction F17, and indicates which of the peptides is expected and observed in each case. For all six subunits, all the predicted peptides with $\mathrm{m} / \mathrm{z}$ between 500 and 5000 were observed by MALDI QqTOF. However, three peptides are common to all six subunits, and two pairs (BAB78740 and BAB78745, BAB78743 and BAB78744) share identical sets of five predicted peptides with four peptides common to all four subunits. The presence of BAB78741 and BAB78742 are perhaps the most definitive, since they both have one predicted peptide not present in the others.

Table 4. Identification of LMW glutenin subunits based on peptide patterns obtained in the MALDI QqTOF instrument and intact mass measured with linear MALDI TOF

\begin{tabular}{lccccccc}
\hline Identified subunit & Database code & HPLC & $\begin{array}{c}\text { Peptide } \\
\text { coverage (\%) }\end{array}$ & $\begin{array}{c}\text { Max. } \\
\text { coverage (\%) }\end{array}$ & $\begin{array}{c}\text { Obs'd mass } \\
\text { (kDa) }\end{array}$ & $\begin{array}{c}\text { Pred. mass } \\
(\mathrm{kDa})\end{array}$ & $\begin{array}{c}\text { Trunc. mass }^{\mathrm{a}} \\
(\mathrm{kDa})\end{array}$ \\
\hline \hline Group 3 type II & BAB78740 & F17 & 22 & 22 & 42.18 & 42.00 & 40.70 \\
Group 3 type II & BAB78741 & F17 & 26 & 26 & 42.18 & 42.02 & 40.71 \\
Group 3 type II & BAB78742 & F17 & 22 & 22 & 42.18 & 42.00 & 40.69 \\
Group 3 type II & BAB78743 & F17 & 24 & 24 & 37.52 & 38.79 & 37.48 \\
Group 3 type II & BAB78744 & F17 & 25 & 25 & 37.52 & 37.21 & 35.89 \\
Group 3 type II & BAB78745 & F17 & 26 & 26 & 34.27 & 35.82 & 34.05 \\
Group 2 type I & BAB78738 & F18 & 25 & 37 & 37.84 & 39.45 & 37.50 \\
\hline
\end{tabular}

aTruncated mass after removal of the signal peptide. 
Table 5. Ulryptic and alkylated peptides in the mass range of 500 to $5000 \mathrm{da}$, from LMW glutenin subunits

\begin{tabular}{|c|c|c|c|c|c|c|c|}
\hline \multirow[b]{2}{*}{ Peptides $(+H)(D a)$} & \multicolumn{6}{|c|}{ Group 3 type II } & \multirow{2}{*}{$\frac{\text { Group } 2 \text { type I }}{\text { BAB } 78738}$} \\
\hline & BAB 78740 & BAB 78741 & BAB 78742 & BAB 78743 & BAB 78744 & BAB 78745 & \\
\hline 637.33 & - & - & - & - & - & - & $x$ \\
\hline 651.35 & V & V & V & V & $V$ & V & - \\
\hline 946.50 & V & V & - & - & - & $V$ & - \\
\hline 1109.56 & - & - & V & V & $V$ & - & - \\
\hline 1195.64 & - & - & - & - & - & - & $V$ \\
\hline 1622.81 & - & $V$ & - & - & - & - & - \\
\hline 1677.85 & V & $V$ & V & V & $V$ & V & - \\
\hline 2030.03 & - & - & V & - & - & - & - \\
\hline 2060.05 & V & V & - & V & $V$ & V & - \\
\hline 2074.06 & - & - & - & - & - & - & $x$ \\
\hline 2323.98 & - & - & - & - & - & - & $\times$ \\
\hline 2767.42 & - & - & - & - & - & - & $V$ \\
\hline 3443.57 & $V$ & $V$ & V & V & $V$ & V & - \\
\hline 4524.30 & - & - & - & - & - & - & $V$ \\
\hline
\end{tabular}

$\sqrt{ }$ : predicted and observed; $\times$ : predicted but not observed; - : not predicted.

For@he@entatively@dentified@MW@roup@2@ypeđ subunit(BAB78738),(\$hree@f(he@ix@redicted $\$$ eptides were@bserved@n@he@MALDI@qTOF@eptide@attern (data@not@shown).CAChigher@mass@peptide@was@also identified@atC5426.3@Da,Cwhich@matches@aCpredicted peptide@t(5426.2(1)a.@ow,@nly@Gew@DNAequences for@his@roup@have@een@etermined@n@ontrast $₫$ o $₫$ he group@@ubunits@iscussed@bove $\$ 20]$.

The@ntact@nasses@f(che@dentified@roteins@erived from@heir(DNA@equences@ive@easonable@natches@o the@bserved@eaks@n@heđinear@MALDICTOF@pectra (Table@).(he@redicted@nasses@re@etermined@fter@he

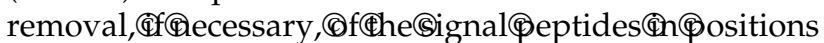
1థo@4 4http \\:www.cgs.dtu.dk/services/SignalIP-2.0). However,@uch@omparisons@f@intact@protein@masses must@e@iewed@vith@aution@ince@ome@f@he@loned LMW@ubunits@enes@sed@o@educe@he@equence@nay have@ontained@eletions@f@he@epetitive@omain $\$ 21]$ resulting@n@underestimation@f@he@ctual@MW.@Moreover, Cseveral@of@the@subunits@have@intact@molecular weights@too@similar@o@be@resolved@byđinear@MALDI TOF.

\section{Conclusions}

The@esults@rom@his@tudy@how@hatबR-HPLC@ombined@with@MALDI@mass@spectrometry@MS)Chas@the capability@o@ffectively@ssess@he@omplexity@f@heat gluten@proteins, CandCto@provide@reasonably@accurate intact@nass@ssignments.đn@ombination@vith@nalysis of@ryptic@igestsథy@MALDI@qTOF, $₫$ his@pproach@lso shows@otential@or@he@dentification@f@pecific@ $\$ M W$ andథMW@lutenin@ubunits,@hich@re@rimary@eterminants@f@wheat@processing@quality.CThe@use@of@sequence@ata@rom@MS/MS@measurements@an@e@ery valuable,Cand@occasionally@essential,@to@improve@the confidence@in 9 rotein@ssignments. $\$$ he@dentification@f gluten@rotein(by@his@pproach@s@urrently@hampered
by@theClack@ofCavailable@DNA@sequences@for@gluten protein,@he@elatively@ow@evels@f@rginine@nd@ysine in these proteins, which produces mainly large peptides, and the close similarity in sequences among groups of these subunits.

\section{Acknowledgments}

The authors acknowledge support for this work by grants from the Natural Sciences and Engineering Research Council of Canada.

\section{References}

1. MacRitchie, F. Physiocochemical Properties of Wheat Proteins in Relation to Functionality. Adv. Food Nutr. Res. 1992, 36, 1-87.

2. Bietz, J. A.; Simpson, D. G. Electrophoresis and Chromatography of Wheat Proteins: Available Methods and Procedures for Statistical Evaluation of the Data. J. Chromatogr. 1992, 624, 53-80.

3. Payne, P. I. Genetics of Wheat Storage Proteins and the Effect of Allelic Variation on Bread-Making Quality. Ann. Rev. Plant Physiol. 1987, 38, 141-153.

4. Cornish, G. B.; Skylas, D. J.; Siriamornpun, S.; Békés, F.; Larroque, O. R.; Wrigley, C. W.; Wootton, M. Grain Proteins as Markers of Genetic Traits in Wheat. Aust. J. Agric. Res. 2001, 52, 1161-1171.

5. Dworschak, R. G.; Ens, W.; Standing, K. G.; Preston, K. R.; Marchylo, B. A.; Nightingale, M. J.; Stevenson, S. G.; Hatcher, D. Analysis of Wheat Gluten Proteins by Matrix-Assisted Laser Desorption/Ionization Mass Spectrometry. J. Mass Spectrom. 1998, 33, 429-435.

6. Mann, M.; Hendrickson, R. C.; Pandey, A. Analysis of Proteins and Proteomes by Mass Spectrometry. Annu. Rev. Biochem. 2001, 70, 437473.

7. Shewry, P. R.; Tatham, A. S. The Prolamin Storage Proteins of Cereal Seeds: Structure and Evolution. Biochem. J. 1990, 267, 1-12.

8. Marchylo, B. A.; Hatcher, D. W.; Kruger, J. E.; Kirkland, J. J. ReversedPhase High-Performance Liquid Chromatographic Analysis of Wheat Proteins Using a New, Highly Stable Column. Cereal Chem. 1992, 69 , 371-378.

9. Godovac-Zimmermann, J.; Brown, L. R. Perspectives for Mass Spectrometry and Functional Proteomics. Mass Spectrom. Rev. 2001, 20, 1-57.

10. Hickman, D. R.; Roepstorff, P.; Shewry, P. R.; Tatham, A. S. Molecular Weights of High Molecular Weight Subunits of Glutenin Determined by Mass Spectrometry. J. Cereal Sci. 1995, 22, 99-103.

11. Foti, S.; Maccarrone, G.; Saletti, R.; Roepstorff, P.; Gilbert, S.; Tatham A. S.; Shewry, P. R. Verification of the cDNA Deduced Sequence of Glutenin Subunit 1Dx5 and an M-r 58,000 Repetitive Peptide by Matrix-Assisted Laser Desorption/Ionization Mass spectrometry (MALDI-MS). J. Cereal Sci. 2000, 31, 173-183.

12. Cunsolo, V.; Foti, S.; Saletti, R.; Gilbert, S.; Tatham, A.; Shewry, P. R. Structural Studies of Glutenin Subunits 1Dy10 and 1Dy12 by MatrixAssisted Laser Desorption/Ionization Mass Spectrometry and High- 
Performance Liquid Chromatography/Electrospray Ionization Mass Spectrometry. Rapid Commun. Mass Spectrom. 2003, 17, 442-454.

13. Loboda, A. V.; Krutchinsky, A. N.; Bromirski, M.; Ens, W.; Standing, K. G. A. Tandem Quadrupole/Time-of-Flight Mass Spectrometer with a Matrix-Assisted Laser Desorption/Ionization Source: Design and Performance. Rapid Commun. Mass Spectrom. 2000, 14, 1047-1057.

14. Dachkevitch, T.; Redaelli, R.; Biancardi, A. M.; Metakovsky, E. V.; Pogna, N. E. Genetics of Gliadins Coded by the Group 1 Chromosomes in the High-Quality Bread Wheat Cultivar Neepawa. Theor. Appl. Genet. 1993, 86(2/3), 389-399.

15. Werner, W. E. Ferguson Plot Analysis of High Molecular Weight Glutenin Subunits by Capillary Electrophoresis. Cereal Chem. 1995, 72, 248-251.

16. Seilmeier, W.; Valdez, I.; Mendex, E.; Wieser, H. Comparative Investigations of Gluten Proteins from Different Wheat Species. II. Characterization of Omega-Gliadins. Eur. Food Res. Technol. 2001, 212, 355-363.
17. Zhang, W.; Chait, B. ProFound: An Expert System for Protein Identification Using Mass Spectrometric Peptide Mapping Information. Anal Chem. 2000, 72, 2482-2489.

18. Halford, N. G.; Field, J. M.; Blair, H.; Urwin, P.; Moore, K.; Robert, L.; Thompson, R.; Flavell, R. B.; Tatham, A. S.; Shewry; P. R. Analysis of HMW Glutenin Subunits Encoded by Chromosome 1A of Bread Wheat (Triticum aestivum L.) Indicates Quantitative Effects on Grain Quality. Theor. Appl. Genet. 1992, 83, 373-378.

19. Shewry, P. R.; Halford, N. G.; Tatham, A. S. The High Molecular Weight Subunits of Wheat Glutenin. J. Cereal Sci. 1992, 15, 105-120.

20. Ikeda, T. M.; Nagamine, T.; Fukuoka, H.; Yano, H. Characterization of New Low Molecular-Weight Glutenin Subunit Genes in Wheat. Theor. Appl. Genet. 2002, 104, 680-687.

21. Masci, S.; D'Ovidio, R.; Lafiandra, D.; Kasarda, D. D. Characterization of a Low-Molecular-Weight Glutenin Subunit Gene from Bread Wheat and the Corresponding Protein that Represents a Major Subunit of the Glutenin Polymer. Plant Physiol. 1998, 118, 1147-1158. 